\title{
Therapeutic potential of herbs against diabetes
}

\author{
Beenish Ehsan ${ }^{1}$, Muhammad Qasim ${ }^{1 *}$, Mahmmad S Masoud ${ }^{1}$, Mahmood ur Rehman ${ }^{1}$, shah Jahan², \\ Usman Ali Ashfaq ${ }^{1}$. \\ 1-Department of Bioinformatics and Biotechnology, Government College University Faisalabad (GCUF), Pakistan. \\ 2-Department of immunology and virology, University of health sciences(UHS) Lahore, Pakistan. \\ *Corresponding author email: qasemawan@gmail.com
}

\section{Review Article}

\section{Abstract}

Diabetes mellitus is a complicated endocrine disorder affecting the major organs like liver, kidneys, heart and eyes and is rapidly affecting world population. According to WHO estimation, it might affect 300 million or more people in future. There is a need to discover new therapies for controlling this serious disease. Synthetic drugs have variable side effects whereas herbal medicine enjoys the benefit of very low side effects, therapeutically potent, low price and easy availability. People have diverted more attention on using these herbal remedies and researchers have diverted attention on developing safer drugs from plants to cure different ailments. There is also need to develop drugs for curing this serious ailment. Present review describes the recent exploration of different medicinal plants using streptozotocin induced animal models of rats and rabbits.

\section{Introduction}

Diabetes mellitus is a serious metabolic disorder of endocrine system effecting considerable population. Diabetes is a disorder indicating insufficient insulin production or increasing resistance to its performance [1-3]. Chemical agents are used generally to treat this upsetting disease but herbal treatments for diabetes have been used in patients with insulin dependent and non-insulin-dependent diabetes, diabetic retinopathy, diabetic peripheral neuropathy, etc. [1]. Diabetes is rapidly influencing the world population and especially type 2 diabetes with 90-95\% occurrence resulting from impaired insulin production or consumption whereas World Health Organization estimated that it might affect the 300million or more population till 2025. Many oral hypoglycemic agents like biguanides, glinides and sulfonylureas are in use today to manage diabetes but they possess adverse side effects, so the research is focused mostly on the discovery of safer antidiabetic agents [4].

\section{Herbal Approach}

Despite of advancements in the field of medicine, diabetes is still like a challenge causing mortality and morbidity in the world. Today, herbal products are in demand for the treatment of diabetes especially type two diabetes. There are various remedies to reduce complications caused by diabetes. Several investigations have been carried out to introduce herbal formulations; due to minor side effects and low cost $[5,6]$.

The quickly rising occurrence of diabetes mellitus is becoming a serious threat to human health in all over the world. During the last few years, bioactive drugs have been isolated from plants showing anti-diabetic potential. However, conventional medicine exhibited a good clinical practice and is showing a glowing future in the treatment of diabetes mellitus. Many studies have been carried out to prove the benefits of medicinal plants with hypoglycemic effects for managing the diabetes mellitus. The effects of these plants may delay the progress of diabetic complications and correct the metabolic abnormalities [7, 8].

Herbal medicines have exhibited anti-diabetic activity through conventional usage. Researchers have proved that the anti-diabetic activity of medicinal plants is due to the presence of phenolic compounds, flavonoids, terpenoids, coumarins and other ingredients which show hypoglycemic activity like Accacia catechu, Vitex negundo, Murraya koenigii etc. [9].

\section{Animal Models for Diabetes Mellitus}

Animal models provide opportunity to understand the pathophysiology and genetic and environmental factors leading to the development of disease and its complications, and thus providing insights for properly treating humans with new therapeutic agents with associated features. Most experiments are performed on rodents, even though other species with human-like biological characteristics are also used. Animal models can be obtained by either spontaneously or by using chemical agents or by surgical, genetic and dietary manipulations and represent many clinical features of disease. In recent years, various new genetically modified animal models including generalized knock-out, tissues pecific knockout and transgenic mice have been devised for studying diabetes [10, 11].

A large number of animal models have been devised for evaluating mechanism of actions of potential antidiabetic drugs and pathogenesis of Diabetes Mellitus [12]. Pharmacologically, streptozotocin and alloxan are widely used for the induction of diabetes in the experimental models. These drugs selectively 
destroy pancreatic beta cells while leaving the remaining pancreatic function intact and are used in small animals (mice, rabbits and cat). Investigator must ensure the minimization of pain and suffering in the experimental animal and this is legal and ethical responsibility of the researcher. Several animal models of diabetes are currently accessible. It is necessary to determine the animal model providing new insights into the respective problem. Species appropriateness must consider for performing experiment. Appropriate use of these animal models must be investigated to test the hypothesis and minimize the risk to animal [12]. The present review reveals the current discoveries on herbal therapeutics for diabetes using streptozotocin induced diabetic animal models. The following part presents the recent phytotherapeutic discoveries for diabetes.

\section{Plants investigated for anti-diabetic activity}

Ferula assafoetida

Asafoetida, an oleo-gum-resin obtained from the roots of Ferula assafoetida, is used for the treatment of different diseases like gastrointestinal disorders, epilepsy, influenza and asthma in traditional medicine system. The hypoglycemic activity of Asafoetida was evaluated in streptozotocin induced Male Wistar diabetic rats. The asafoetida extract showed significant hypoglycemic activity at dose of $50 \mathrm{mg} / \mathrm{kg}$ for 4 weeks, indicating the presence of the tannins and phenolic acids (ferulic acid) in the extract [13].

\section{Stevia rebaudiana}

Aqueous extract of Stevia rebaudiana in combination of Momordicha charantia, Tamarindus indica, Gymnema sylvestre, Allium sativum and Murraya koenigii were evaluated for antidiabetic activity in the form of different polyherbal combinations. All these combinations were studied for their acute toxicity, Oral glucose tolerance test in normal rats, antidiabetic and anti- $\alpha$ amylase and $\alpha$-glucosidase activity and liver function tests were checked. All combinations were safe and dose of $250 \mathrm{mg} / \mathrm{kg}$ was selected. Polyherbal combinations II showed significant antidiabetic activity indicating that tannins sterols and flavonoids may be present in this combination [14].

\section{Adenanthera pavonina Linn.}

Antihyperglycaemic and lipid lowering effects of Adenanthera pavonina seed aqueous extract (APSAE) was evaluated in the streptozotocin induced diabetic rats. Treatment with APSAE showed considerable decrease $(\mathrm{P}<0.01)$ in plasma glucose, elevated levels of serum triglyceride and cholesterol levels were significantly decreased $(\mathrm{P}<0.01)$ by APSAE. APSAE treatment for 30 days showed significant decrease in serum LDL-cholesterol
$(\mathrm{P}<0.01)$ and significant increase in serum $\mathrm{HDL}$ cholesterol level $(\mathrm{P}<0.01)$ and elevated the levels of HbA1c which was significantly increased $(\mathrm{P}<0.05)$ indicating that extract has the potential to treat diabetes condition and associated lipid disorders [15].

\section{Panax ginseng}

Historically, Panax ginseng has been used as herbal medicine. Antidiabetic efficiency of Panax ginseng berry extract was evaluated in streptozotocin induced diabetic mice. Hypoglycemic potential of extract in beta-cell deficient mice was evaluated and mechanisms involved were evaluated. Extract showed promising results stimulating increased insulin secretion indicating beta-cell regeneration and improved glycemic control [16].

\section{Cassia javanica}

Kumavat et al., investigated the ornamental and therapeutically less acknowledged plant Cassia javanica for hypoglycemic ability in streptozotocin induced diabetic rats. First of all, drug was used to test acute oral toxicity. Formerly, phytochemistry of drug was checked by standard qualitative tests thus detecting antidiabetic compounds. Single and numerous doses of drug were given to rats under investigation. The conditions studied, were serum cholesterol, serum triglycerides, serum proteins, and blood glucose. These conditions were examined using acute and sub-acute treatment of test drug. The test drug and standard drug demonstrated considerable fluctuations in the abnormal levels of serum metabolites of diabetic rats[17].

\section{Ocimum Gratissimum}

Aqueous leaf extract of Ocimum gratissimum (OG) was administered orally in streptozotocin induced Albino Wistar rats and parameters like water intake, food and weight changes were estimated. The extract was administered per oral to the diabetic-treated (DMT) groups at a dose of $1500 \mathrm{mg} / \mathrm{k}$ body weight daily for 28 days. Results indicated that Ocimum gratissimum reduces blood sugar level in diabetic rats and alleviate the cardinal symptoms of diabetes mellitus namely; polyphagia, polydypsia and weight loss [18].

Thymeleae hirsute L.

Antidiabetic and antihypertensive potential of a polyphenol rich-fraction of Thymeleae hirsuta $\mathrm{L}$ was investigated in streptozotocin induced type-2 diabetic model and NO-deficient hypertension in rats. The polyphenol-rich fraction from Thymelaea hirsute showed improvement in hyperglycemia and blood pressure increment. This might be due to the presence of polyphenols and extract can be beneficial as food supplement to prevent type-2 diabetes and hypertension [19]. 


\section{Murraya koenigii and Ocimum tenuflorum}

Antidiabetic potential of Murraya koenigii (L.) Spr. and Ocimum tenuflorum L. was evaluated in streptozotocin-induced diabetic Swiss mice. Adjuuvant therapy of $M$. koenigii (chloroform; MKC) and O. tenuflorum (aqueous; OTA) extracts resulted in proper glucose consumption with an increment in liver glucose-6-phosphate dehydrogenase enzyme activity, and normal glycogenesis in hepatic and muscle tissues, inhibition of pancreatic and intestinal glucosidase, reduction in postprandial hyperglycemia with concomitant increase in glucose metabolism, prolonged glucosidase inhibition, endogenous insulin secretion also after treatment, protection of pancreatic $\beta$-cell and functional pancreatic islets [20].

Aegle marmelos (L.)

Antidiabetic effect of Aegle marmelos (L.) Corr. (Rutaceae) bark extract was investigated in streptozotocin induced rats for a period of 30 days. Methanolic extract was evaluated for a number of biochemical parameters; blood glucose, total protein, hepatic glycogen, glycated haemoglobin (HbAlc), marker enzymes of hepatic function, carbohydrate metabolism and plasma insulin. Phytochemical studies revealed the presence of lupeol $(0.29 \% \mathrm{w} / \mathrm{w})$, aegelin $(1.27 \% \mathrm{w} / \mathrm{w})$ as potent antihyperglycemic agents. Histology revealed the $\beta$-cells regenerative effects of extract indicating the efficient antidiabetic potential [21].

\section{Adenanthera pavonina}

Therapeutic effects of Adenanthera pavonina L., Leguminosae-Mimosaceae seeds aqueous extract (APSAE) on streptozotocin induced diabetic rats for diabetic neuropathy Different biochemical parameters were evaluated in a dose dependent manner for $0,4,8$ and 12 weeks respectively. Levels of thermal, colder, spontaneous motor activity and motor co-ordination alterations were examined. Histology of sciatic nerve was examined to check nerve stability. Results indicated the neuroprotective effects of extract as compared with pregabalin [22].

\section{Caesalpinia bonduc}

Hydro-methanolic extract of Caesalpinia bonduc was evaluated for different diabetic complications in diabetic rat models. The extract $(250 \mathrm{mg} / \mathrm{kg})$ was administered orally for 21 days. Treatment resulted in the significant $(P<0.05)$ improvement in carbohydrate metabolizing enzymes, antioxidant enzymes like superoxide dismutase and catalase, toxicity assessment enzyme parameters, glycogen levels, blood glucose and lipid peroxidation levels detecting beneficial effects of $C$. bonduc as potent antihyperglycemic and antioxidant agent [23].

\section{Juglans regia}

Mohammadi et al., evaluated the antihyperglycemic properties of the Juglans regia leaf extract in streptozotocin nicotinamide induced diabetic rats. One week after stimulation of diabetes, Juglans regia extract and Metformin have been administered orally continuously for 4 weeks. Fasting blood sugar, body weight, serum lipids and insulin level were examined in decided groups. A noteworthy reduction of glucose, HbA1c, total cholesterol and serum triglycerides were observed after 4 weeks in rats treated with Juglans regia extract compared to the control groups indicating Juglans regia a potent sntidiabetic agent [24].

\section{Euphorbia hirta}

Ethanolic extract of Euphorbia hirta was evaluated in streptozotocin induced diabetic rats for therapeutic effects using glibenclamide as standard. The extract $(400 \mathrm{mg} / \mathrm{kg}$ ) was administered orally and effects were checked for the time intervals of $0,7^{\text {th }}, 14^{\text {th }}$ and $21^{\text {st }}$ days. Reduction in blood glucose was significant at $7^{\text {th }}$ day after continuous administration and also showed the improvement in lipid profile; triglycerides, cholesterol, low density lipoprotein, very low density lipoprotein and high density lipoprotein indicating antihyperlipidemic and hypoglycemic potential [25].

\section{Talinum Triangulare}

Antihyperglcemic effects of Talinum Triangulare were evaluated in streptozotocin induced experimental animals, glucose loaded, and in healthy rats. Extract $(250 \mathrm{mg} / \mathrm{kg})$ was administered for 2 weeks. Extract significantly reduced the blood glucose levels in diabetic and normal glucose (1.2 $\mathrm{g} / \mathrm{kg}$ ) loaded rats. Oral glucose tolerance test showed significant hypoglycemia in rats. The use of glipizide with extract showed significant synergistic effect [26].

\section{Symplocos cochinchinesis}

Therapeutic effects of $S$. cochinchinensis bark methanolic extract (SCBe) were examined in diabetic rats using glibenclamide as standard. Extract at the dose of 250 and $500 \mathrm{mg} / \mathrm{kg}$ for 28 days respectively showed improvement in plasma insulin, blood glucose, total protein, urea, creatinine, modified plasma enzymes and liver glycogen. Extract also showed improvement in lipid parameter alterations. Results and in vitro studies indicated the antioxidant, antilipidemic and antidiabetic effects of SCBe [27].

Otostegia persica

Aqueous extract of Otostegia persica was evaluated in streptozotocin-induced diabetic male Wistar rats $(150-200 \mathrm{~g})$. The extract showed significant $(\mathrm{p}<0.05)$ hypoglycemic activity at the different doses especially at $400 \mathrm{mg} / \mathrm{kg}$ as compared with diabetic 
control group. Histology revealed the decrease in the mass and number of $\beta$ - cells of pancreases and improvement in serum triglycerides, and homeostasis especially in T400 group of animals [28].

\section{Rosmarinus officinalis L.}

Water extract of $R$. officinalis leaf was evaluated for diabetic nephropathy in streptozotocin induced diabetic rats compared with control rats. Extract (200 $\mathrm{mg} / \mathrm{kg}$ body weight) was administered for 21 days. Extract showed significant hypoglycemic activity and reduction oxidative stress markers. Extract enhanced the Serum enzymatic and non enzymatic antioxidants indicating the reducing effect of extract on oxidative stress [29].

\section{Semecarpus anacardium}

Semecarpus anacardium nut milk extract $(200 \mathrm{mg} / \mathrm{kg}$ boy weight) was orally administered to high-fat diet streptozotocin-Induced diabetic rats in comparison with metaformin (500 $\mathrm{mg} / \mathrm{kg}$ body weight) as standard. Extract was administered for 30 days to evaluate the parameters; fasting blood glucose, insulin, HbA1c levels, haemoglobin, HOMA- $\beta$ and HOMA-IR were measured, and also the levels of lipid peroxidation and antioxidant enzymes were observed. Extract showed the hypoglycemic potential, enhanced the levels of antioxidant enzymes, decreased lipid peroxidation and HbA1c. Extract showed significant $(p<.05)$ results indicating antidiabetic and antioxidant potential of extract [30].

Mirabilis jalapa L.

Ethanolic extract of Mirabilis jalapa L. root (EEM) was administered to normal and streptozotoin induced diabetic mice to evaluate effects of extract on insulin, hyperglycemia and lipid profile for 28 days. Extract was administered continuously at intervals of $2,4,8 \mathrm{~g} / \mathrm{kg}$. Continuous administration of extract at dose of $4,8 \mathrm{~g} / \mathrm{kg}$ showed improved insulin index, decreased blood glucose, serum total cholesterol and triglyceride levels in muscle and liver tissue with enhanced glycogen levels in these tissues [31].

\section{Cinnamomum Zeylanicum}

Aqueous bark extract $(200 \mathrm{mg} / \mathrm{kg})$ of Cinnamomum zeylanicum was administered orally to type 1 diabetic rat models created by streptozotocin. Extract administration significantly $(p<0.05)$ improved the lipid profile; Total cholesterol (TC), triglyceride (TG), LDL-cholesterol (LDL) and VLDL-cholesterol (VLDL) levels in diabetic animals by 12.5, 23.86, 14.96 and $20 \%$ respectively and elevated the tissue glycogen and HDL-cholesterol significantly. Extract also showed improvement in glucose homeostatic enzymes indicating the antidiabetic activity of the extract [32].

\section{Theobroma cacao L.}

The autolyzed powder of two clones (PBC 140, UIT1) of Theobroma cacao L. without the presence of polyphenols, fat and alkaloid were analyzes in streptozotocin-induced diabetic rats for therapeutic purposes. The autolysates generated under the $\mathrm{pH}$ of 3.5 were effective inhibitors of $\alpha$-amylase whereas $\alpha$ glucosidase activity was not examined. Autolysates showed effective hypoglycemic activity after four hours of administration. Assays showed the presence of high quantities of hydrophobic amino acids in autolysates indicating that these might be responsible for therapeutic potential [33].

\section{Tamarindus indica Linn.}

Keeping in view the presence of flavonoids and polyphenols in tamarind, aqueous extract of Tamarindus indica Linn. was orally administered to streptozotocin-induced male Wistar rats for the evaluation of antidiabetic effect till four weeks. Extract significantly improved the expression of glucose transporter-2, glucose transporter-4, and islets' intracellular calcium levels and $\beta$-cell regeneration, mRNA expression in liver and muscle cells and insulin secretion. Extract also controlled the levels of glycosylated hemoglobin, nitric oxide and tumor necrosis factor $\alpha$. [34].

\section{Ocimum sanctum}

Aqueous extract of Ocimum sanctum was evaluated for the antioxidant potential in streptozotocin-induced diabetic rats. Extract was administered through oral route for thirty days. Extract decreased the levels of thiobarbituric acid reacting substances in plasma and improved conditions of the antioxidant enzymes; glutathione peroxidase, superoxide dismutase and catalase in essential organs like kidney and liver. Results indicated that Ocimum sanctum might be an important herbal medicine for curing diabetic complications [35].

\section{Areca catechu $\mathrm{L}$.}

Areca catechu L. (Palmaceae) was evaluated for the antidiabetic activity in streptozotocin- induced diabetic Wistar rats. Three leaf extracts; methanolic, chloroform and petroleum ether, were administered daily ( $200 \mathrm{mg} / \mathrm{kg}$ body weight) via oral path for 15 days using glibenclamid $(0.5 \mathrm{mg} / \mathrm{kg})$ as reference dug. Extracts showed significant $(p<$ 0.001 ) hypoglycemic activity on examining at every $5^{\text {th }}$ day while methanolic extract proving better active extract [36].

Calamintha officinalis Moench.

Antihyperglycemic potential of Calamintha officinalis Moench., was evaluated in streptozotocininduced diabetic model and in normal animals. Water extract of aerial parts of plant was administered via oral route daily for 15 days. Extract showed 
significant improvement in insulin index and plasma glucose levels indicating hypoglycemic activity of extract [37].

\section{Bauhinia purpurea}

Methanolic extract of bark of Bauhinia purpurea was used to evaluate anti-diabetic activity in streptozotocin induced diabetic rats in comparison with normal rats. The experimental animals showed significant hypoglycemic activity of extract in a dose dependent manner. Antidiabetic effect might be due to the existence of flavonoids because flavonoids stimulate the insulin secretion, $\beta$-cell proliferation, inhibition of cyclooxygenases as proved from previous studies [38].

\section{Cassia fistula}

Aqueous extract and gold nanopaticles were synthesized using Cassia fistula stem bark. Gold nanoparticles showed considerable changes in body weight and in serum glucose. Nanoparticles showed significant improvement in functions of kidney and liver and in the lipid profile in comparision with aqueous extract and reduction in serum biochemistry parameters. Results indicated that gold nanoparticles could be used as an efficient therapy for curing diabetic complication [39].

\section{Clausena anisata}

The southern African medicinal native Clausena anisata (Wild) Hook is used for treating different diseases. The anti-diabetic effects of crude C. anisata leaf extracts were evaluated both in vivo and in vitro. The experiment proved that methanolic aqueous extracts showed efficient inhibition $(>80 \%)$ of $\alpha-$ amylase than glucose-6-phosphatase inhibition in rabbit liver $(60$ and 58\%). Acetone extract administration in rats failed to control postprandial hyperglycemia. Acetone extract also showed potent inhibition (> 80\%) of Bacillus stearothermophillus $\alpha$ glucosidase and human urinary $\alpha$-amylase. However, the hypoglycemic effect of extract may not be due to the inhibitory effects on carbohydrate related enzymes [40].

\section{Melothria heterophylla}

The ethanolic extracts of Melothria heterophylla aerial parts were administered to streptozotocininduced diabetic Swiss albino rats at the dose of 200 and $400 \mathrm{mg} / \mathrm{kg}$, body weight. The plant extract and its active components showed significant $(p<0.01)$ control on blood glucose and serum enzymes including insulin. Rutin and gallic acid showed efficient (69.1 and 66.7\%, respectively) hypoglycemic activity at the dose of $2 \mathrm{mg} / \mathrm{kg}$ and also enhanced the body weight and serum insulin in diabetic rats indicating the anti-diabetic activity of all experimental components [41].

\section{Corn Silk}

Corn silk polysaccharides were extracted using distilled water and precipitated using $80 \%$ solution of ethanol. The resulting extract was administered in streptozotocin-induced diabetic rats for the demonstration of anti-diabetic activities. The daily administration of the extract $(100-500 \mathrm{mg} / \mathrm{kg}$ body weight) exhibited significant reduction in blood glucose and serum lipid levels. The polysaccharides also exhibited anti-depressant potential against dimethyl-biguanide in diabetic animals indicating a dose dependent behavior [42].

\section{Rosemary}

Rosemary is an important dietary food used in everyday life in our food recipes to increase taste and flavor. Rosemary aqueous extract was administered in streptozotocin-induced diabetic rats for 4 weeks to study the anti-diabetic mechanisms of the extract. Rosemary extract perfusion resulted in the improvement of diabetes related parameter; decreased the sugar (20\%), cholesterol (22\%), triglyceride $(24 \%)$, low density lipoprotein $(27 \%)$ levels and increased high density lipoprotein (18\%) level showing significance at $(\mathrm{P}<0.01)$ and $(\mathrm{P}<$ 0.05), respectively [43].

\section{Cassia auriculata L.}

The methanolic extract of Cassia auriculata L. flowers was administered in streptozotocin-induced diabetic rat models to evaluate antioxidant and antidiabetic potential. The inhibitory potential of extract on glucosidase and amylase was evaluated using acarbose as standard whereas biochemical parameters were studied using glibenclamid as reference drug. The extract resulted in the improvement of glucose level, glutathione, antioxidant enzyme potential, insulin level, DPPH radical scavenging ability and antilipid peroxide. Phytochemical analysis indicated the existence of quercetin, caffeine and catechins clueing the treatment of different diseases [44].

Elytraria acaulis Lind.

Methanolic extract of Elytraria acaulis Lind. was administered at the dose of 200 and $400 \mathrm{mg} / \mathrm{kg}$ using glibenclamid $(500 \mathrm{mcg} / \mathrm{kg})$ as reference drug via the oral administration in diabetic rats. The high dose $(400 \mathrm{mg} / \mathrm{kg}$ ) of extract showed improved control on oral glucose tolerance test, bodyweight, and serum hemoglobin and liver glycogen levels. Histology of organs; liver, kidney and pancrease revealed the improved structures of islets of langerhans, hepatocytes, inhibition of glomerular hypertrophy and glomerulosclerosis indicating the antioxidant and anti-diabetic property of extract [45].

\section{Emblica officinalis}

Hydro-methanolic (20:80) extract of Emblica officinalis Gaertn. leaves, was administered in 
diabetic rats at different doses for 45 weeks to study the anti-diabetic effects using glibenclamid as reference. The extract showed improved blood glucose and serum insulin level at a noteworthy significance $(P<0.05)$ and showed significant $(P<0.05)$ decrease in biochemical parameters. The extract also improved the free radicals scavenging and antioxidant enzymes; superoxide dismutase, catalase, glutathione peroxidase and glutathione in dose dependent way [46].

\section{Gmelina arborea}

The ethanolic extract $(150 \mathrm{mg} / \mathrm{kg})$ of Gmelina arborea (Verbenaceae) was administered in male Wistar albino rats to study anti-diabetic effect comparing with glibenclamid $(100 \mu \mathrm{g} / \mathrm{kg})$. Significant hypoglycemia resulting from dose administration in rats might be due to modulated $\beta$-cell function or glucose absorption in tissues or intestinal glucose uptake inhibition. The significant changes resulting from dose administration was comparable with standard drug glibenclamid [47].

Eugenia jambolana and Cinnamomum zeylenicum Different polyherbal formulations of Eugenia Jambolana-seed and Cinnamomum zeylenicum-bark were observed for in vitro antidiabetic activity. APKJ 004 polyherbal formulaion showed efficient antidiabetic activity to use for experimental study in wistar rats. The results indicated the increased absorption ability of APKJ $004(112.3 \pm 6.68 \mathrm{mg} / \mathrm{dl})$ than glibenclamid $(93.4 \pm 4.67 \mathrm{mg} / \mathrm{dl})$ and APKJ 004 decreased the glucose level $(97.01 \pm 6.23 \mathrm{mg} / \mathrm{dl})$ and increased the insulin level $(06.75 \pm 0.96 \mu \mathrm{U} / \mathrm{ml}--$ $23.13 \pm 0.35 \mu \mathrm{U} / \mathrm{ml})$ as compared to glibenclamid. The phytochemical studies have detected the presence of glycosides, tannins, anthocyanins, flavonoids, alkaloids indicating its further use for experimental purposes [48].

\section{Prosopis farcta}

The southeastern Iranian plant (Prosopis farcta) extracts were investigated in male wistar rats for antidiabetic wound healing properties. 24 animals were divided into four groups. Three holes of $4 \mathrm{~mm}$ size on both dorsal sides of all rats were made to study wound healing effect of extracts on holes. The diabetic extract treated groups with root aquatic extract and fruit pod powder demonstrated the reduction in holes diameter efficiently $(p<0.05)$ and holes closed soon than in diabetic control group. Results revealed the skin regenerative effect of Prosopis farcta and its use in traditional medicine due to different therapeutic properties [49].

\section{Geigeria alata}

The methanolic extract of Sudanese medicinal plant; Geigeria alata, was administered at different doses in streptozotocin-induced diabetic rats orally for chronic treatment (14 days) or acute treatment (2 hours). The high dose $(250 \mathrm{mg} / \mathrm{kg})$ resulted in the reduction of blood glucose and enhanced the serum insulin with modulation of $\beta$-cells. In vitro analysis showed the improved anti-oxidant status and $\alpha$-glucosidase inhibition, indicating the use of plant for controlling diabetes [50].

\section{Guar gum}

Diet containing different percentages $(0 \%, 5 \%, 10 \%$ and $20 \% \mathrm{w} / \mathrm{w}$ ) of guar gum was administered to streptozotocin induced diabetic rats for evaluating antidiabatic potential at $0,7.14$ and 28 days interval comparing with glibenclamid (a reference drug). Guar gum improved the lipid index, polyuria, polyphagia, body weight, diet ingestion $(P<0.05)$, insulin activity, glucose levels resulting from diabetes induction. Experiment proved that the administration of guar gum in larger dose than glibenclamid is effective for controlling diabetic complications proving guar gum a reliable soluble fiber for body digestion [51].

\section{Malva parviflora}

The popular Mexican Malva parviflora was analyzed in the diabetic rats for antidiabetic potential. Different extracts (methanol, chloroform and hexane) were tested for lipid and cholestrol index, glucose and glycogen levels, insulin and antioxidant status, hepatic enzymes and protein glycation. Hexane extract reversed the abnormalities induced by streptozotocin in the rats indicating the interaction of plant components with targets that induce diabetes pathogenesis [52].

\section{Phaleria macrocarpa}

Phaleria macrocarpa fruit extracts were analyzed in normal and diabetic rats for hypoglycemic potential for a period of 12 days. Only methanol extract decreased blood glucose by 56.25 and $58.33 \%$ $(\mathrm{P}<0.05)$ and plasma insulin by 75 and $50 \%(\mathrm{P}<0.05)$ compared with diabetic control and pre-treatment values. Results indicated that methanol extract contains terpenoids, tannins and flavonoids indicating that anti-diabetic potential of $P$. macrocarpa can be directed also by extra-pancreatic means [53]

\section{Curcumin}

Pharmacokineic and pharmacodynamic effects of glimepiride was checked using curcumin as adjuvant therapy and study was evaluated in diabetic mice. Pharmacokinetic parameters $\left(\mathrm{AUC}_{0}\right.$ to $\mathrm{n}, \mathrm{AUC}$ total, $\mathrm{C}$ max, $\mathrm{t}_{1 / 2}$ and MRT) were observed by administering glimepiride $(1 \mathrm{mg} / \mathrm{kg})$ on 8th day in one group, following cucumin $(80 \mathrm{mg} / \mathrm{kg})$ in another group for 7 days and glimepiride $(1 \mathrm{mg} / \mathrm{kg}$ ) following curcumin on $8^{\text {th }}$ day in same group whereas pharmacodynamic investigation was evaluated by using curcumin alone or as adjuvant with glimepiride at different 
concentrations in rats for 28 days. Blood samples and serum samples were investigated using High performance liquid chromatography and results indicated that curcumin prevents deviations in biochemical parameters and improves the consumption of glimepiride in the body. So, there is a need to optimize correct concentration of both ingredients for preparing better therapy [54].

\section{Green Tea Extract}

Green tea extract $(1.5 \%$, w/v) was administered to the Diabetic Wistar rats. Experimental diabetes enhanced the ALP, AST, ALT, bilirubin and malondialdehyde index whereas reduction was observed in parameters; albumin, SOD, GSH, GSH-Px and CAT. Histopathological changes were consistent with the biochemical alterations. Extract administration improved the all hepatic tissue injury related parameters significantly $(P<0.05)$ and significantly reduced the blood glucose levels. Other reports also indicate the hypoglycemic properties but there is a need of much work related to antioxidant and hepatoprotective effects [55].

\section{Salvia reuterana}

Ethanolic extract of Salvia reuterana aerial parts was administered to diabetic wistar rats at different doses comparing with glibenclamid $(600 \mathrm{mg} / \mathrm{kg})$ for 14 days. Extract at the doses of 0.25 and $0.5 \mathrm{~g} / \mathrm{kg}$ body weight improved the urea, creatinine, uric acid, insulin index, lipid disorders, serum glucose, alanine aminotransferase and aspartate aminotransferase providing evidence to control diabetes using aerial parts of Salvia reuterana [56].

Sesbania sesban (L) Merr.

Aqueous extract of Sesbania sesban (L) Merr. leaves was administered to diabetic rats to investigate attenuating effects on sciatic nerves using pregabalin (10 mg/kg, p.o.) as standard for 12 weeks. The extract improved the total calcium levels, superoxide anion and tail flick latency and attenuated axonal degeneration in treated rats indicating neuroprotective effects. Motor co-ordination and motor activity observed at different time periods during study have no prominent changes as well as behavioral alterations remained as such during whole study period [57].

\section{Trichosanthes dioica and Clitoria ternatea}

Leaf extracts of Clitoria ternatea and Trichosanthes dioica (200 and $400 \mathrm{mg} / \mathrm{kg}$ body weight) in combination or separately were administered to diabetic wistar rats and different biochemical parameters like glycosylated hemoglobin, insulin, glucose levels, globulin, albumin, urea, creatinine and proteins were analyzed. Antidiabetic potential was investigated for 28 days comparing with libenclamid effect at the dose of $600 \mu \mathrm{g} / \mathrm{kg}$ in one animal group. The treatment improved the body weight and reduced the serum glucose level $(\mathrm{p}<0.05)$ [58].

\section{Tinospora cordifolia}

Alcoholic extract of Tinospora cordifolia stem was used in two fractions (Basic fraction and Ethyl acetate soluble fraction) for evaluating antidiabetic ability in diabetic Wistar rats. Extracts at the dose rate of 100 and $200 \mathrm{mg} / \mathrm{kg}$ body weight were administered orally during entire experiment and resulted in the improved lipid profile, blood glucose, liver glycogen, blood urea and hemoglobin. Basic fraction showed improved antidiabetic status indicating its use in diabetic therapy to improve insulin release. Research is at peak to further identify its active ingredients [59].

\section{Vernonia amygdalina and Azadirachta indica}

Ethanolic extracts of Vernonia amygdalina Del. (VA) and Azadirachta indica A. Juss (AI) were administered adjuvantly (200 $\mathrm{mg} / \mathrm{kg}, 50: 50)$ to normal and diabetic rats to study antidiabetic mechanisms comparing with medium acting insulin, $\mathrm{HU}$ (5 IU/kg, s.c.). After 28 days treatment with extracts, improvement was observed in the antioxidant enzymes, $\alpha$-amylase, liver glucose levels and histopathology of pancreas and liver revealed the reversing effects on pathological changes significantly $(P<0.05)$. Extract decreased $(P<0.05)$ the T3, T4 and serum insulin by 1.57 and 2.16 and 1.66 fold, respectively indicating distinctive and total recovery when both extracts (VA/AI) are employed in combination rather than partial [60].

\section{Conclusion}

Herbal remedies provide a promising therapy indicating negligible side effects than oral hypoglycemic drugs. Research has been carrying out to explore the therapeutic potential of medicinal plants for curing diabetes mellitus. Medicinal plants have been proved useful for controlling different diabetic complications. Mostly herbs have been tested for their effects on beta-cells, insulin level, glucose level, oxidative stress and different biochemical parameters. The present review describes the recently proved herbal therapeutics for managing diabetes. There is a need to explore more potential of herbal remedies by exploring their phytoconstituents, related beneficial effects, toxicity studies and mode of actions. There is also need to optimize their dosage and combinatorial effects with different drugs and herbs for synthesizing an effective biomedicine for different human ailments. Researchers could get benefit from this data to explore more potential from these herbs to synthesize effective drugs. 


\section{References}

1. Singh, U., A. Kochhar., and S. Singh. (2011). Blood glucose lowering potential of some herbal plants. Journal of Medicinal Plant Research, 5 (19), 4691-4695.

2. Joseph, B. and D. Jini (2011).Insight into the hypoglycaemic effect of traditional indian herbs used in the treatment of diabetes. Res. J. Med. Plant, 5, 352-376.

3. Mutalik, S., et al., (2003). Preliminary studies on acute and subacute toxicity of an antidiabetic herbal preparation, Dianex. Indian J Exp Biol, 41(4): p. 316-20.

4. Patel, D.K., et al., (2012) An overview on antidiabetic medicinal plants having insulin mimetic property. Asian Pacific journal of tropical biomedicine,2(4), 320-330.

5. Srivastava, S., V.K. Lal., and K.K. Pant, (2012). Polyherbal formulations based on Indian medicinal plants as antidiabetic phytotherapeutics. Phytopharmacology, 2(1), 1-15.

6. Perera, P.K. and Y. Li. (2011).Mushrooms as a functional food mediator in preventing and ameliorating diabetes. Funct Foods Health Dis, 4, 161-171.

7. Malviya, N., S. Jain., and S. Malviya.(2010). Antidiabetic potential of medicinal plants. Acta Pol Pharm, 67(2), 113-118.

8. Kavishankar, G.B., et al., (2011). Diabetes and medicinal plants- A review. Int J Pharm Biomed Sci, 2(3), 65-80.

9. Talukdar, A., et al., (2012). Antidiabetic Activity of some Medicinal Plants found in various region of assam. International Journal of Ayurvedic and Herbal Medicine, 2(2).

10. Javia, S., et al., (2011). Animal models for type-2 diabetes mellitus: a review. International Journal of Pharmaceutical Research and Development, 3(12), 23-33.

11. Srinivasan, K. and P. Ramarao (2007). Animal models in type 2 diabetes research: an overview. Indian J Med Res, 125(3), 45172.

12. Lasker, S.P. and R. Raihan. (2010). Animal Research In Diabetes And Ethical Consideration. Bangladesh Journal of Bioethics, 1(2), 20-23.

13. Iranshahi, M. and M. Alizadeh. (2012). Antihyperglycemic effect of Asafoetida (Ferula assafoetida Oleo-Gum-Resin) in streptozotocin-induced diabetic rats.
World Applied Sciences Journal, 17(2),157162.

14. Patil, A., et al., (2012). Antidiabetic effect of polyherbal combinations in STZ induced diabetes involve inhibition of $\alpha$-amylase and $\alpha$-glucosidase with amelioration of lipid profile. Phytopharmacology, 2(1),46-57.

15. Pandhare, R.B., et al., (2012). Antihyperglycaemic and lipid lowering potential of Adenanthera pavonina Linn. in streptozotocin induced diabetic rats. Oriental Pharmacy and Experimental Medicine, 12(3), 197-203.

16. Park, E.Y., et al., (2012). Increase in Insulin Secretion Induced by Panax ginseng Berry Extracts Contributes to the Amelioration of Hyperglycemia in Streptozotocininduced Diabetic Mice. J Ginseng Res, 36(2), 153-60.

17. Kumavat, U.C., S.N. Shimpi, and S.P. Jagdale. (2012). Hypoglycemic activity of Cassia javanica Linn. in normal and streptozotocin-induced diabetic rats. Journal of advanced pharmaceutical technology \& research, 3(1), 47.

18. Owo, D.U., et al., (2012). Oral administration of aqueous leaf extract of ocimum gratissimum ameliorates polyphagia, polydipsia and weight loss in streptozotocininduced diabetic rats. American Journal of Medicine and Medical Sciences, 2(3), 45-49.

19. Bnouham, M., et al., (2012). Antidiabetic and antihypertensive effect of a polyphenol-rich fraction of Thymelaea hirsuta L. in a model of neonatal streptozotocin-diabetic and NG-nitro-l-arginine methyl ester-hypertensive rats. Journal of Diabetes, 4(3), 307-313.

20. Dusane, M.B. and B.N. Joshi.(2012). Islet protective and insulin secretion property of Murraya koenigii and Ocimum tenuflorum in streptozotocin-induced diabetic mice. Canadian journal of physiology and pharmacology, 90(3), 371-378.

21. Gandhi, G.R., S. Ignacimuthu, and M.G. Paulraj. (2012). Hypoglycemic and $\beta$-cells regenerative effects of Aegle marmelos (L.) Corr. bark extract in streptozotocin-induced diabetic rats. Food and Chemical Toxicology, 50(5), 1667-1674.

22. Pandhare, R.B., et al., (2012). Attenuating effect of seeds of Adenanthera pavonina aqueous extract in neuropathic pain in 
streptozotocin-induced diabetic rats: an evidence of neuroprotective effects. Revista Brasileira de Farmacognosia, 22(2), 428435.

23. Jana, K., et al., (2012). Antihyperglycemic and antioxidative effects of the hydromethanolic extract of the seeds of Caesalpinia bonduc on streptozotocininduced diabetes in male albino rats. Pharmacognosy research, 4(1), 57-62.

24. Mohammadi, J., et al., (2012). The effect of hydro alcoholic extract of Juglans regia leaves in streptozotocin-nicotinamide induced diabetic rats. Pak. J. Pharm. Sci, 25(2), 407-411.

25. Maurya, A.K., et al., (2012). Antidiabetic and antihyperlipidemic effect of Euphorbia hirta in streptozotocin induced diabetic rats. Der Pharmacia Lettre, 4(2), 703-707.

26. P., R.B., et al., (2012). Hypoglycemic Activity of Methanolic Extract of Talinum Triagulare Leaves in Normal and Streptozotocin Induced Diabetic Rats. Journal of Applied Pharmaceutical Science, 2(5), 197-201.

27. Sunil, C., et al., (2012). In vitro antioxidant, antidiabetic and antilipidemic activities of Symplocos cochinchinensis (Lour.) S. Moore bark. Food and Chemical Toxicology, 50(5), 1547-1553.

28. Akbarzadeh, S., et al., (2012). Anti-diabetic effect of Otostegia persica extract on diabetic rats. J. Med. Plants Res, 6(16), 3176-3180.

29. Khalil, O.A., et al., (2012). Antidiabetic activity of Rosmarinus officinalis and its relationship with the antioxidant property. African Journal of Pharmacy and Pharmacology, 6(14), 1031-1036.

30. Khan, H.B.H., et al., (2012). Antidiabetic and antioxidant effect of Semecarpus anacardium Linn. nut milk extract in a high-fat diet STZinduced type 2 diabetic rat model. Journal of Dietary Supplements, 9(1), 19-33.

31. Zhou, J., et al., (2012).Hypoglycemic and hypolipidemic effects of ethanolic extract of mirabilis jalapa L. Root on normal and diabetic mice. Evidence-Based Complementary and Alternative Medicine,

32. Hassan, S.A., et al., (2012). Aqueous bark extract of Cinnamomum Zeylanicum: a potential therapeutic agent for streptozotocininduced type 1 diabetes mellitus (T1DM) rats. Tropical Journal of Pharmaceutical Research, 11(3), 429-435.
33. Sarmadi, B., et al., (2012). Hypoglycemic effects of cocoa (Theobroma cacao L.) autolysates. Food chemistry, 134(2), 905911.

34. Sole, S.S. and B.P. Srinivasan, (2012). Aqueous extract of tamarind seeds selectively increases glucose transporter-2, glucose transporter-4, and islets' intracellular calcium levels and stimulates $\beta$-cell proliferation resulting in improved glucose homeostasis in rats with streptozotocininduced diabetes mellitus. Nutrition Research.

35. Muralikrishnan, G., S.K. Pillai, and F. Shakeel. (2012). Protective effects of Ocimum sanctum on lipid peroxidation and antioxidant status in streptozocin-induced diabetic rats. Natural product research, 26(5), 474-478.

36. Mondal, S., S. Bhattacharya, and M. Biswas. (2012). Antidiabetic activity of Areca catechu leaf extracts against streptozotocin induced diabetic rats. Journal of Advanced Pharmacy Education \& Research, 2(1),1017.

37. Singh, P.P., et al., (2012). A Review on phytochemical and pharmacological potential of Calamintha officinalis Moench. IJPSR, 3(4), 1001-1004.

38. Pahwa, S., R. Mazumder, and S. (2012). Bhattacharya, Antidiabetic activity of methanolic extract of bark of Bauhinia purpurea. International Journal of Pharmaceutical Sciences and Research, 3(5), 1444-1447.

39. Daisy, P. and K. Saipriya. (2012). Biochemical analysis of Cassia fistula aqueous extract and phytochemically synthesized gold nanoparticles as hypoglycemic treatment for diabetes mellitus. International journal of nanomedicine, 7,1189-1202.

40. Mogale, M.A., et al., (2012). The effects of Clausena anisata (Wild) Hook leaf extracts on selected diabetic related metabolizing enzymes. Journal of Medicinal Plants Research, 6(25), 4200-4207.

41. Mondal, A., T.K. Maity, and D. Pal. (2012). Hypoglycaemic effect of Melothria heterophylla in streptozotocin-induced diabetic rats. Pharmaceutical Biology, 50(9), 1151-1156.

42. Zhao, W., et al., (2012). Comparison of antidiabetic effects of polysaccharides from corn silk on normal and hyperglycemia rats. 
International journal of biological macromolecules, 50(4), 1133-1137.

43. Aljamal, A., et al., (2012). Effects of rosemary on lipid profile in diabetic rats. African J of Plant Sci,. 6(7), 222-225.

44. Jyothi, S.G., S.C.S. Somashekaraiah, and B.V. Chavanand. (2012). In vitro and In vivo Antioxidant and Antidiabetic Efficacy of Cassia auriculata L. Flowers. Global Journal of Pharmacology, 6(1), 33-40.

45. K., K.R., K.B. Raj, and M. Azamthulla. (2012). Anti Hyperglycemic Activity of Elytraria Acaulis Lind. on StreptozotocinInduced Diabetic Rats. Medicinal \& Aromatic Plants, 1(103).

46. Nain, P., et al., (2012). Antidiabetic and antioxidant potential of Emblica officinalis Gaertn. leaves extract in streptozotocininduced type-2 diabetes mellitus (T2DM) rats. Journal of Ethnopharmacology, 142(1), 65-71.

47. Punitha, D., et al., (2012). Antihyperlipidemic effect of ethanolic leaf extract of Gmelina arborea in streptozotocin induced male wistar albino rats. Pharmacology and Toxicology, 2(3), 46-51.

48. Amarachinta, P.R. and K. Jamil. (2012). Preclinical Evaluation Of Polyherbal Formulations: Hypoglycemic Activity In Rats. International journal of ayurvedic and herbal medicine, 2(2), 218-228.

49. Ranjbar-Heidari, A., et al., (2012). The Effect of Fruit Pod Powder and Aquatic Extract of Prosopis farcta on Healing Cutaneous wounds in Diabetic Rat. Zahedan Journal of Research in Medical Sciences, 14(5), 16-20.

50. Hafizur, R.M., et al., (2012). The antidiabetic effect of Geigeria alata is mediated by enhanced insulin secretion, modulation of $\beta$ cell function, and improvement of antioxidant activity in streptozotocin-induced diabetic rats. Journal of Endocrinology, 214(3), 329-335.

51. Saeed, S., et al., (2012). Antihyperglycemic and antihyperlipidemic effects of guar gum on streptozotocin-induced diabetes in male rats. Pharmacognosy magazine, 8(29), 65-72.
52. Gutierrez, R.M.P. (2012). Evaluation of hypoglycemic activity of the leaves of malva parviflora in streptozotocin-induced diabetic rats. Food \& Function, 3(4), 420-427.

53. Ali, R.B., et al., (2012). Hypoglycaemic and anti-hyperglycaemic study of Phaleria macrocarpa fruits pericarp. J Med Plants Res, 6(10), 1982-1990.

54. Rani, T.S., S. Sujatha, and C. Veeresham. (2012). Pharmacokinetic and Pharmacodynamic Interaction of Curcumin with Glimepiride in Normal and Diabetic Rats. Pharmacog commun, 2(3), 14-21.

55. Abolfathi, A.A., et al., (2012) Protective effects of green tea extract against hepatic tissue injury in streptozotocin-induced diabetic rats. Evidence-Based Complementary and Alternative Medicine, 10.

56. Eidi, A., et al., (2012). Effect of Salvia reuterana aerial parts on serum parameters in normal and streptozotocin-induced diabetic rats. Journal of Society for development in new net environment in B\&H, 6(4), 11991206.

57. Pandhare, R.B., et al., (2012). Attenuating effect of Sesbania sesban (L) Merr. extract on neuropathic pain in streptozotocin-induced diabetic rats: an evidence of neuroprotective effects. Phytopharmacology, 2(1), 190-201.

58. Kavitha, R. and V. Premalakshmi. (2012). Studies on the Synergetic Effect of Trichosanthes dioica and Clitoria ternatea Leaf Extract on the Streptozotocin-Induced Diabetic Rats. International Journal of Research in Pharmaceutical and Biomedical Sciences, 3(3), 1056-1064.

59. Selvaraj, S., et al., (2012). Fractions of Tinospora cordifolia stem extract demonstrate insulin secreting activity in diabetes induced Wistar rats. Journal of Pharmacy Research Vol, 5(3), 1424-1427.

60. Atangwho, I.J., et al., (2012). Synergistic antidiabetic activity of Vernonia amygdalina and Azadirachta indica: Biochemical effects and possible mechanism. Journal of Ethnopharmacology, 141(3), 878-887. 